\title{
Reseñas
}

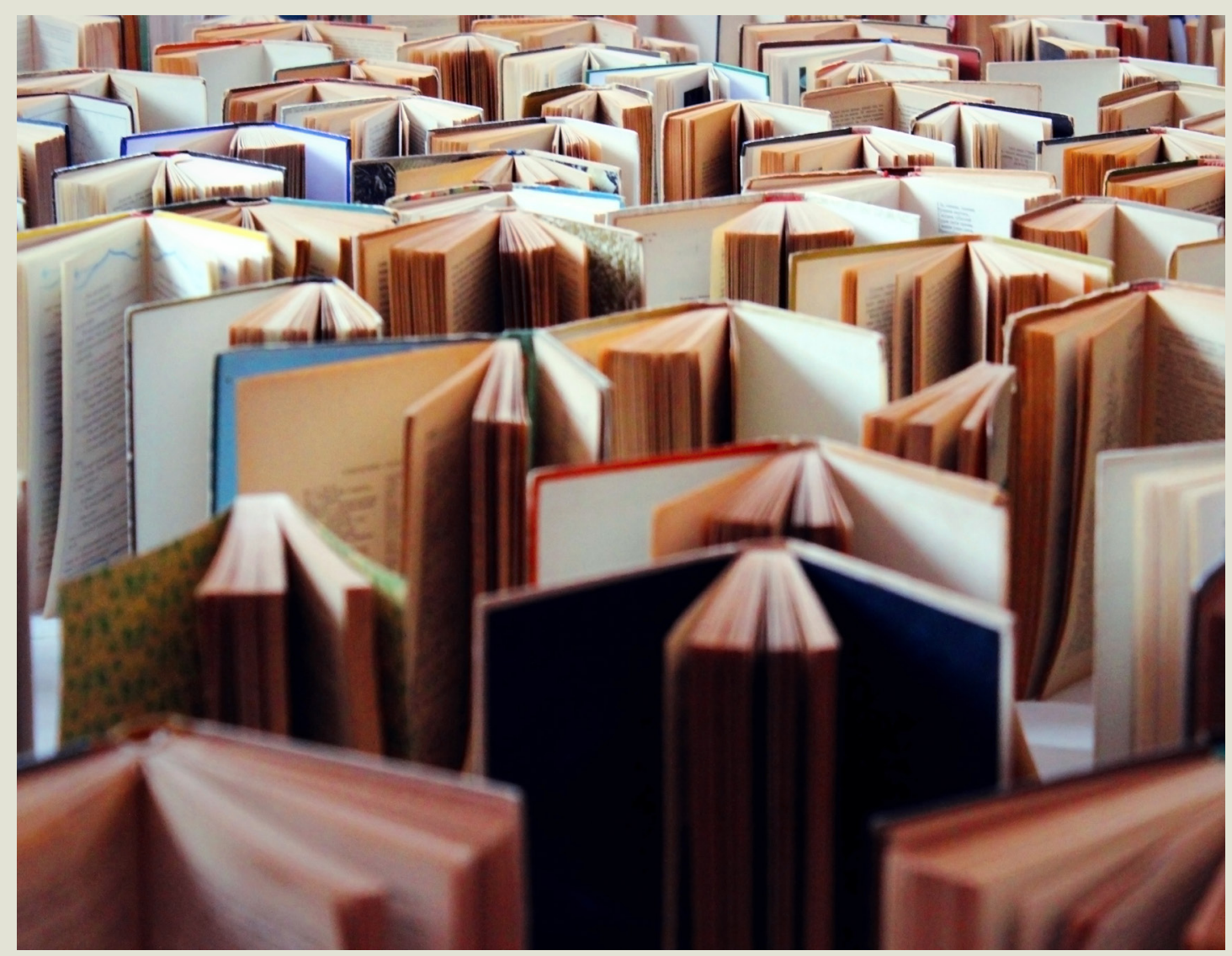




\title{
La verdad como ilusión y territorio en disputa
}

Mecanismos de la posverdad (2017).

Jacqueline Fowks. Lima: Fondo de Cultura Económica.

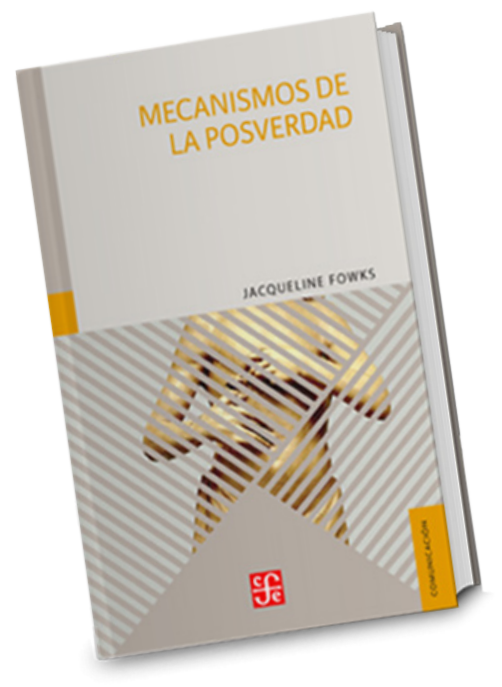

Por Eduardo Villanueva Mansilla (Pontificia Universidad Católica del Perú, Lima)

\begin{abstract}
onectar el debate público con la reflexión académica es un trabajo delicado. La velocidad de la discusión contemporánea, azuzada ya no solo por los medios masivos, sino por la superposición de opiniones y alaridos en redes varias, hace difícil establecer una línea de base para la conversación. Definir lo que se discute es tan importante como el acto mismo de discutirlo, y si algún aporte pueden hacer los académicos es establecer con cierta claridad conceptos que delimiten la conversación; así se logra contener los excesos de la opinión, aunque no siempre se puedan evitar los desbordes partidarios.

Pero vivimos en tiempos de troles y bots, aunque todavía escribamos libros. Los primeros pueden reaccionar en segundos, mientras que el libro más modesto tiene maduración lenta, de meses quizá si somos privilegiados, de años habitualmente. Aportar al debate y fijar la conversación alrededor de nociones debatibles, pero sensatas es cada vez más lejano.
\end{abstract}


Afortunadamente, Jacqueline Fowks ha logrado proponernos una ruta para la discusión racional en un tema que es casi metaconceptual: cómo definir, caracterizar y estudiar precisamente eso que hace cada vez más dificultoso discutir deliberativamente los grandes temas de interés público. Entender cómo se interviene en la discusión pública precisamente para alejarla de una base sensata y coherente, llevándola a las visiones partidarias y alejadas de la evidencia, resulta importante, aunque no necesariamente fácil. La así llamada posverdad aparece como un conjunto de prácticas discursivas dedicadas a ignorar o alterar la noción de que existe una realidad objetiva sobre la cual es posible construir juicios de valor que, sin descartar las perspectivas políticas o morales en conflicto, cuando menos se asuman relacionadas a eso que los periodistas suelen llamar verdad: la enunciación fundamentada de los acontecimientos ya ocurridos.

Esta tendencia no es precisamente nueva. Su forma más coloquial fue definida en el 2005 por - adecuadamente - un comediante: Stephen Colbert propuso en su programa satírico que lo que importaba en los actuales tiempos no era la verdad, sino lo que llamó truthiness, la condición de creer que algo es verdadero, el aserto de que algo es verdad porque así lo creemos. La construcción social de la realidad llevada a su conclusión lógica, podríamos decir.

Aplicar el concepto de truthiness de manera consistente puede llevar, entonces, a que aquello que otros llamarían propaganda o engaño sea tan solo un intento de negar la veracidad de nuestra manera de ver la realidad; de nuestra afirmación de la capacidad colectiva de apreciar y entender el mundo de forma certera. No hay una valoración moral tras la truthiness: se puede ser cínico o sincero, pues lo importante es la convicción del discurso.

La posverdad, por tanto, es la actualización seria de una idea satírica de hace más de diez años. Como todo buen concepto, sirve para articular y comprender la realidad; como toda buena explicación de prácticas de comunicación, es una aproximación empírica que constata la práctica concreta de los que comunican y documenta la manera en que estas prácticas son usadas en distintos contextos y ocasiones. Fowks opta por centrarse en la realidad de la posverdad peruana, como ejemplo complementario de América Latina: el territorio es nuestra política, y los actores que practican la posverdad, el Estado, los partidos políticos, son los actores privados de la política peruana. Pero los actuantes, es decir, los que efectivamente hacen aquello que llamamos posverdad son los que 
dan vida a lo que Fowks considera fábricas de realidad: todos los agentes que han cubierto el espacio que antes era el dominio de la prensa y del periodismo; los nuevos alimentadores de la opinión pública, que invaden desde lo digital y lo personal, y que contagian con sus prácticas a las esferas más formales de una prensa que cada día más, cortesía de las transformaciones digitales, cuenta con menos recursos y depende más de favores ajenos.

Fowks nos propone en su libro un recorrido sistemático, bien explicado y mejor documentado, del territorio en el que actores y actuantes transforman la realidad construyéndola discursivamente, con fines muy distintos del ideal republicano y liberal que todavía ilumina siquiera de costado la formación de periodistas y la tarea de la prensa. Lo hace en pocas páginas, lo que es un mérito, y con un lenguaje limpio, pero llano. Una crítica negativa emerge de ahí: el libro es quizá más árido de lo necesario, entre otras razones por la abundancia de digresiones a pie de página; como trata de muchos elementos que se encuentran en medios digitales, resulta ser difícil de leer sin acceder con facilidad a los enlaces. Es un libro de ensayo académico, accesible a un lector informado, pero con aportes relevantes para la formación profesional de periodistas y para la iluminación de estudiantes de introducciones a la comunicación social; pero podría beneficiarse de un enlace maestro, de una página web con todos los enlaces que se ofrecen a lo largo del texto.

Esto no quita potencia al argumento central sobre la posverdad y la demanda de una esfera pública más responsable y sincera para los peruanos. Recordemos que en la base misma de un gobierno republicano yace la confianza en que, como propuso el abate Sieyès, todos somos el tercer Estado: todos somos iguales y todos constituimos la soberanía, sin privilegios de cuna o de función. El encargo de ejercerla, entregado a lo que llamamos gobierno, requiere un acto de confianza, un public trust, que en inglés se refiere a la confianza pública tanto como a la encarnación de dicha confianza en un aparato estatal orientado al interés público. Aunque no siempre se sepa exactamente qué es interés público, se supone que el proceso político debería llevarnos a alcanzar cierto consenso sobre sus contornos, basados en un acuerdo democrático, republicano, sobre el que fundamos todo. Ese public trust no solo nos declara iguales, sino que nos exige actuar como iguales, sobre todo frente al otro, al que tenemos delante, y que no tiene las mismas oportunidades que uno: carece de los medios, las relaciones, el tiempo o simplemente la agudeza para ejercer su parte de la vida en común. Los débiles, los que 
están en desventaja, están en la consideración misma de la noción de una república moderna.

Una república así construida garantiza el diálogo y la creación de consenso, y postula que sus conflictos pueden ser resueltos dialógicamente en la esfera pública, ahora manifiesta en una combinación de voces no siempre armónicas, que usan medios propios de una sociedad de masas con abundancia comunicativa. Esta esfera se hace evidente gracias a ese cuarto estamento, que no es tal, sino un tejido conectivo que permite vernos y hablarnos: los medios de comunicación y, en particular, la prensa. El ideal republicano implica una prensa activa, dispuesta a dar espacio a todos y a no ceder frente al poder: es más, que esté dispuesta a decirle sus verdades al poder.

Claro, es una aspiración, pero que en América Latina no ha sido, casi nunca, ya no alcanzada, sino siquiera aludida como un destino al cual llegar. Por siglos, los que detentan el poder lo hacen para su propio beneficio, en una expresión antirrepublicana de privilegio que ni siquiera intenta postular que lo hacen para todos; apenas por ratos se ofrece que se hace lo que se hace por el progreso, para que haya obras o para que formas de caridad, generosidades genéricas de la autoridad, mejoren ligeramente la vida de algunos compatriotas. Ignorarlos, y peor aún, ignorarlos sistemáticamente, como hemos hecho en el Perú, invalida la noción misma de una república. No tiene, entonces, nada de extraño que algunos opten por usar a la prensa como una extensión de la representación de sus intereses, y que en el proceso terminen deteriorando un poco más la posibilidad de encontrar ese public trust que necesitamos para funcionar como país, no como colección de conflictos.

No cabe duda de que la posverdad ha sido perfeccionada, cortesía de transformaciones sociotecnológicas que afectan al mundo entero, no solo al Perú. Internet, imaginado originalmente como un paraíso de opinión considerada, ha terminado por agudizar hasta el caos la posibilidad de que, con algo de práctica y entusiasmo, cualquier posición logre afirmarse en su propia caja de resonancia, que alimentará generosamente a los que crean en la versión específica de la truthiness que se alienta en cada caso. En donde teníamos una esfera pública construida sobre la cuidadosa y considerada opinión de los gatekeepers, ahora hay una aglomeración de voces que no pretenden guardar las formas ni seguir los pasos de aquellos que, se supone, encarnan responsablemente el rol del cuarto poder. No solo es internet, sin duda: véase Fox News en 
Estados Unidos, o Willax en el Perú, donde la realidad objetiva es apenas un lienzo sobre el cual dibujar ilusiones malintencionadas.

Pero los ciudadanos de países del primer mundo tienen alternativas: una prensa que acepta su rol en el centro de las controversias entre poderes formales, poderes fácticos y sociedad civil permite ampliar el debate y debilitar las tendencias autoritarias. No es garantía de absoluta estabilidad ni tampoco es que todos los medios en semejantes democracias sean impolutos y neutrales: la verdad es una construcción discursiva, como lo es la noticia, y un diario puede optar por iluminar, enmarcar o encaminar la verdad de maneras tales y por motivos tan subalternos en Francia o en el Perú. Finalmente, todo sesgo es reflejo de la manera como construimos esa realidad que no es tan objetiva como quisiéramos creer; pero al menos hay honestidad en los sesgos y, hasta cierto punto, transparencia para reconocer errores.

La detallada y cuidadosa documentación de casos de fabricación de la realidad que Fowks presenta en este libro no deja duda de la capacidad de los medios peruanos para negarse a construir su propia realidad; la opción por utilizar lo que otros les dan no tiene nada de excepcional: la bestia refinada a la que se refería Tom Wolfe suele concordar sutilmente con el poder, por razones de coincidencia y conveniencia. Coincidencia, porque los que toman las decisiones han sido formados y viven en los espacios sociales y políticos de los que también provienen los que deciden qué es la realidad en un medio; conveniencia, porque, al final de cuentas, de ahí viene la publicidad, las ventas, la validación social. La prensa, incluso la más claramente independiente, no existe fuera de la sociedad que la crea y, finalmente, la refleja.

En un contexto así, la abundancia de medios digitales fortalece la posverdad: por cada ciudadano dispuesto a financiar Ojo Público, hay un tejido de medios supuestamente de periodistas que en realidad sirve a intereses disimulados u opacos. Cacofonías múltiples que impulsan sin mucho pudor opiniones que son falazmente llamadas periodismo; y que dicen ser verdaderamente independientes cuando apenas cubren, traslúcidamente, su curiosa coincidencia constante con el poder fáctico que los financia.

¿Un buen ejemplo? Terruco, que aparece como el insulto primordial: descalifica, cambia los términos de la conversación, impide dialogar y encima sirve para convocar lealtades específicas. Perfecta manera de apelar a lo más bajo de la política nacional como imprecación, pe- 
ro también como discurso: el que lo usa quiere quitar por completo la legitimidad del interlocutor, quiere sacarlo de la sociedad y deshumanizarlo hasta hacerlo un apestado social. Y nadie lo cuestiona, nadie lo dice y nadie lo condena. Me alegra leer un argumento tan contundente contra esa práctica nefasta en este libro.

Nuestra posverdad, entonces, resulta siendo la versión local de lo que ocurre en el mundo, pero también es la actualización de prácticas que la prensa ha encarnado por demasiado tiempo. Una exacerbación de estilos centenarios que continúan debilitando nuestra posibilidad de ser una sociedad transparente y una república más allá del nombre. Luchar contra semejante statu quo es imprescindible si queremos sinceramente que el Perú sea de todos, por todos, para todos. La autora merece el agradecimiento de todos por un alegato tan poderoso en favor de ese ideal superior. 


\title{
El diverso cine peruano hecho en las regiones
}

Las miradas múltiples: el cine regional peruano (2017).

Emilio Bustamante y Jaime Luna Victoria. Universidad de Lima, Fondo Editorial.

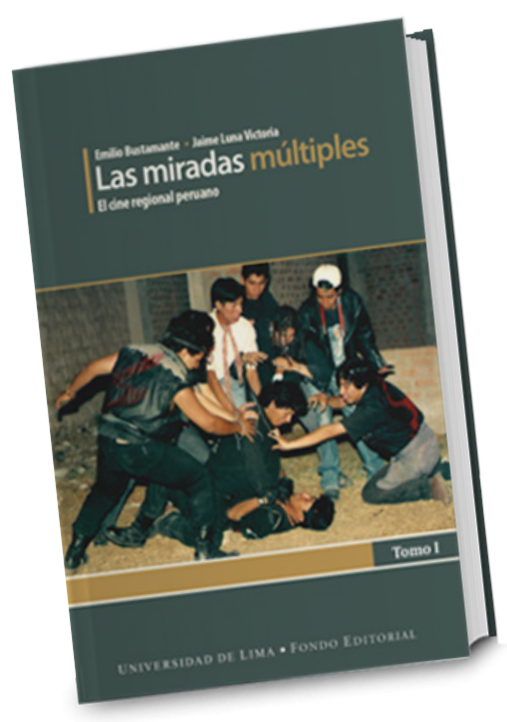

\author{
Por Manuel Eyzaguirre Bravo \\ (Universidad Católica Santo Toribio \\ de Mogrovejo, Chiclayo)
}

\begin{abstract}
T as miradas múltiples: el cine regional peruano es una investigación hecha por el docente Emilio Bustamante y por el crítico y guionista Jaime Luna Victoria para el Instituto de Investigación Científica de la Universidad de Lima. El estudio define al cine regional peruano como aquel "producido y exhibido en las regiones fuera de Lima Metropolitana y Callao, realizado en soporte de película cinematográfica o video (digital o analógico), por empresas (formales o informales) domiciliadas en esas regiones y por cineastas que viven y trabajan allí". Se lleva a cabo un diagnóstico de su historia y realidad, se describe el perfil del cineasta, se comenta un grupo de películas y se evalúa la gestión del Estado en su promoción. Los investigadores han sido rigurosos para identificar a las regiones con más iniciativa cinematográfica, seleccionando sus producciones y mecanismos de
\end{abstract}




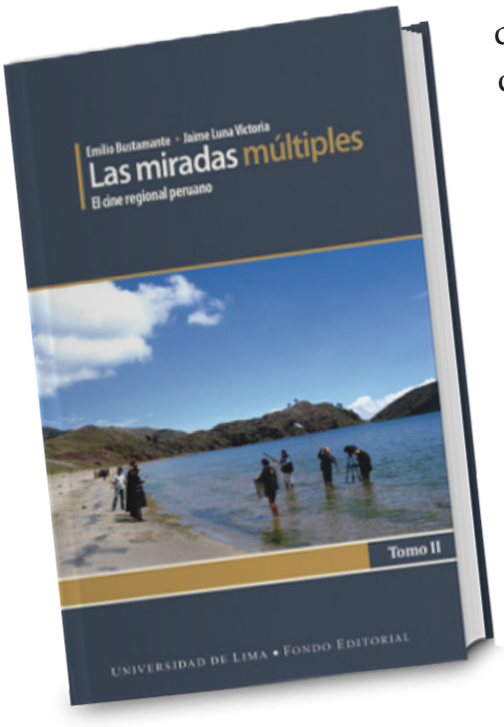

distribución-exhibición. También se introduce al lector en la realidad peculiar de sus realizadores y le añaden una mirada crítica al fenómeno.

El primer tomo tiene una estructura en tres capítulos. El primero explora la génesis del cine regional. Lo sustenta en la llamada democratización cinematográfica que empezó en la década de los noventa, cuando los equipos de registro bajaron sus costos y aumentó la producción de películas. Asimismo, se señala el componente cultural: las tradiciones orales, costumbres, folclore, mitologías, identidad $\mathrm{y}$ problemáticas de sus diferentes realidades que pudieron transmitirse de manera espontánea y cómoda con el uso del lenguaje cinematográfico.

Los cineastas regionales se clasifican desde aquellos dedicados a un cine de ficción con interés popular, que emplean los géneros (la mayoría, en el sur peruano), hasta quienes producen un cine documental de autor, reflexivo, experimental y personal. Igualmente, se describe su condición socioeconómica como clase media rural y clase media urbana. Su mirada diversa se entiende al revisar su formación: hay realizadores cinéfilos, autodidactas y empíricos, con carreras vinculadas al audiovisual y otros con profesiones distantes al medio. Algunos son actores, artistas visuales, personas con proyectos empresariales en el rubro audiovisual y otros, independientes.

Aparecen cifras importantes: 216 películas se produjeron en las regiones peruanas desde el año 1996 hasta el 2015. Los métodos usados para su realización también son estudiados. En el grupo de quienes hacen cine para ser exhibido comercialmente, se hallan iniciativas empresariales, que recurren al autofinanciamiento y al apoyo de sus familias. En muchas ocasiones, se destaca la multifuncionalidad de los cineastas, quienes ocupan cargos de productor, director, camarógrafo e, incluso, como actores. En unos cuantos casos, se trabaja sin guion literario, y se emplean escaletas o esquemas narrativos. Resalta en este grupo el cambio en las dinámicas de producción cuando se obtienen 
fondos del Estado peruano, lo que no siempre significa una mejora del proceso, justamente por algunas etapas que siguen siendo informales.

En el bloque de quienes realizan un cine documental y de autor, la mayoría autofinancia sus proyectos y recurre a fondos del Estado. Algunos proyectos nacen desde el entorno académico (por parte de profesores y alumnos) e incluso por colectivos, asociaciones y empresas propias.

En cuanto a la exhibición y distribución, la investigación muestra que es el gran problema de los cineastas regionales. Ayacucho y Puno destacan por liderar esa vocación comercial, haciendo uso de salas. En otras ciudades del sur, se lleva a cabo una exhibición itinerante; es decir, las películas hacen un recorrido por poblados cercanos o en regiones limítrofes. Se subraya la rentabilidad de algunos proyectos en las dos ciudades antes mencionadas, lo que habla de un interés del público por ver cine como entretenimiento, pero también de emprendimientos al descubrir espacios adecuados para la proyección. Aquí la problemática reside en la aparición de los multicines y su nula colaboración con la cinematografía local. Cabe indicar que no llegan a veinte las películas regionales estrenadas en salas de cine comercial. Frente a este escenario, muchos realizadores optan por editar sus películas en DVD y distribuirlas informalmente en centros comerciales. La publicación evidencia, como tema pendiente, la necesidad de darle un empuje a la presencia de las películas regionales en festivales peruanos y del extranjero.

Entre los géneros más utilizados por los cineastas regionales está el horror, que conecta los mitos, tradiciones y miedos de un entorno social con los recursos estéticos y narrativos del cine comercial hollywoodense. Destacan en este género las regiones de Puno, Junín y sobre todo Ayacucho, donde, según los autores, "habría en los filmes de horror ayacuchano un simbolismo más concreto aún. Representarían la vivencia del terror experimentado durante el conflicto interno armado de los años 1980-2000".

También se encuentra el melodrama, representativo de Juliaca, en la región de Puno, donde se abordan fenómenos socioculturales producto de la intensa migración rural. Con este género, se cuentan historias sobre crisis personales, pérdidas de moral, ética y valores, crisis familiares y hechos trágicos que alteran las estructuras sociales. Otro género es el realismo social, cuyos relatos explicitan la denuncia y los problemas sufridos por las comunidades de algunas zonas del sur peruano, 
haciendo hincapié en historias sobre el terrorismo. En menor medida, se producen películas cómicas, de contenido religioso y moralista, y en casos aislados, cine de artes marciales, wéstern, acción y policiales.

En el documental, las regiones más representativas son Arequipa, Lambayeque, Loreto, Cusco y Cajamarca. Hay propuestas de autor, trabajos por encargo, proyectos universitarios, performativos, de contenido social y cultural. Finalmente, está el cine experimental y la animación, con cineastas de Cusco y Arequipa como promotores de este género.

En cuanto a la narrativa y puesta en escena, las películas de ficción siguen la dramaturgia clásica de inicio, conflicto y desenlace, con su lógica de la causalidad; pero este recurso se debilita en el cine regional por un deficiente trabajo en los diálogos, rupturas de continuidad, falta de formación actoral y de especialización técnica. Esta situación es aceptada por muchos cineastas y, a pesar del escenario, nada detiene su prolífica realización hasta la actualidad.

La mirada lejana y poco analítica señalaría que la estética de sus producciones podría ser menor y que el mérito de esa cinematografía se encontraría solamente desde una perspectiva antropológica. Pero los autores del libro indican que "en los dos tipos de cine regional hay formas narrativas y estilísticas novedosas y altamente expresivas que derivan de la convergencia y el conflicto de tradiciones propias y normas institucionales".

En el segundo capítulo, la investigación selecciona dieciséis regiones por su continuidad y relevancia: en el sur del país, Áncash, Apurímac, Arequipa, Ayacucho, Cusco, Huancavelica, Huánuco, Junín, Puno y Tacna; en el norte, Cajamarca, La Libertad, Lambayeque y Piura; y en la Amazonía peruana, Loreto y Ucayali. Se plantea un repaso histórico de la cinematografía de estas regiones, se menciona a sus representantes, los espacios de exhibición, logros y esos aliados socioculturales que promueven su realización.

El tercer y último capítulo es un rico análisis y descripción de películas representativas en el cine regional. En este apartado, la investigación cobra su nivel más alto: los autores comparten una tarea que recopila fichas técnicas, sinopsis y comentarios. Su mirada es aguda, crítica y nada condescendiente con las producciones regionales. Se fragmentan los trabajos, desde el lenguaje cinematográfico usado, la estructura de los guiones y su tratamiento narrativo-estético para analizar sus motivaciones, influencias, estilos y diversas connotaciones que plantean. 
El segundo tomo recopila entrevistas a 32 cineastas representativos de 12 regiones del Perú. Ayacucho y Puno tienen, cada uno, a 6 realizadores entrevistados, mientras que Junín está representado por 4 cineastas. Son 8 regiones del sur (Apurímac, Arequipa, Ayacucho, Cusco, Huánuco, Junín, Puno y Tacna) las que confirman una numerosa realización cinematográfica en este bloque territorial peruano por sus 25 entrevistados. De la región norte (Lambayeque, La Libertad y Cajamarca) se entrevistó a 6 directores y del oriente peruano (Loreto), un cineasta. Las entrevistas a profundidad usan cuestionarios personalizados, tomando en cuenta factores socioeconómicos y culturales que rodean a los cineastas desde la génesis de sus proyectos hasta la exhibición de sus películas. Se percibe la inquietud de los investigadores por estudiar la personalidad de cada región para desarrollar sus preguntas; asimismo, el conocimiento previo de las obras cinematográficas y el estilo particular de los cineastas.

Los dos tomos hacen visible y documentan la existencia de una sólida cinematografía hecha fuera de la capital. Registra y analiza una forma de hacer cine con veinte años de existencia. Iniciativas con múltiples voces, miradas, propuestas y estéticas que van desde lo comercial hasta lo experimental, desde la ficción tradicional hasta el documental de autor, desde el cortometraje hasta el largometraje. De esta manera, se legitima y valida la existencia de cineastas en las regiones del Perú, sacándolos del anonimato, empoderándolos y rompiendo las fronteras que los dividen del cine producido en Lima. La investigación los vincula a un entorno académico, inscribiéndolos en la historia del cine peruano y en el accionar de una cinematografía peruana que seguirá desarrollándose si acepta incluir al cine regional en sus festivales, diferentes espacios de difusión y políticas gubernamentales.

La publicación debería prolongarse en el tiempo a través de otras investigaciones. Generar un efecto multiplicador en estudiosos de la cinematografía nacional e internacional, críticos, estudiantes de las facultades de Ciencias de la Comunicación, antropólogos y sociólogos; artistas interesados en la creación visual, miembros de cineclubes, centros culturales y cinéfilos. Pero, sobre todo, desarrollar productos de investigación cualitativa y cuantitativa en aquellos líderes involucrados en promover el cine en cada una de las regiones estudiadas y en otras que estén germinando su producción.

Se integra, de manera indirecta, a los cineastas regionales y les permite conocerse a través de su breve historia personal, formación, 
cinefilia y proyectos. Hace que los realizadores sean conscientes de la diversidad de sus trabajos, de sus estilos, de su aproximación a los géneros, de las temáticas abordadas y de las dinámicas de producción, distribución y exhibición. Pero también los alerta sobre los significados y diversas interpretaciones que provocan, ya sea desde una perspectiva artística o antropológica. Los comentarios y análisis de sus obras les sirven para ampliar la mirada de sus trabajos, criticar su labor y reafirmar o cambiar la perspectiva de su propuesta cinematográfica.

Asimismo, consolida la necesidad de generar una filmoteca digital que archive las películas reseñadas y otras obras regionales como material de consulta para futuros proyectos de investigación, pero también como parte de la memoria fílmica peruana. Esta iniciativa serviría como punto de partida para los futuros cineastas regionales, interesados en contar historias respetando la idiosincrasia e identidad de sus contextos, pero potenciando sus esquemas narrativos, la técnica usada y sus mecanismos de distribución y exhibición.

Finalmente, cabe destacar un tema que la investigación subraya en su primer tomo: el papel que juega el Estado en el devenir del cine regional. Coincido plenamente con los autores con respecto a que el Ministerio de Cultura y la Dirección del Audiovisual, la Fonografía y los Nuevos Medios (DAFO) debe entender a profundidad las características y naturaleza del cine regional, y no buscar profesionalizarlo o adaptarlo según los estándares de producción de las películas que se hacen en la capital. En cambio, se deberían establecer firmes políticas de formación para capacitar a los cineastas, con talleres, residencias y laboratorios descentralizados que tengan continuidad, como mínimo, dos veces al año.

Para terminar esta reseña, dejo una poderosa cita del libro:

Una manera que tendría el Estado de contribuir al desarrollo del cine en las regiones sería facilitando el alquiler y el uso de locales públicos para los cineastas que desean exhibir sus películas [...] respaldar el estreno de películas regionales [...] promover la transmisión por la televisión del Estado [...]. En un mediano plazo se podría contemplar la construcción de salas alternativas en las regiones donde se exhiban películas que no tengan un fácil acceso al circuito comercial, emplear de modo planificado los circuitos de exhibición que hoy están en manos de promotores informales, y aprobar una nueva ley de cine donde se considere una cuota de pantalla para que en los multicines comerciales de las regiones se puedan exhibir las películas que allí se producen. 


\title{
Aulas en red: una escuela que evoluciona
}

\section{Pedagogía red. Una educación para tiempos de internet (2016).}

\section{Begoña Gros Salvat y Cristóbal Suárez-Guerrero (editores). Barcelona: Ediciones Octaedro.}

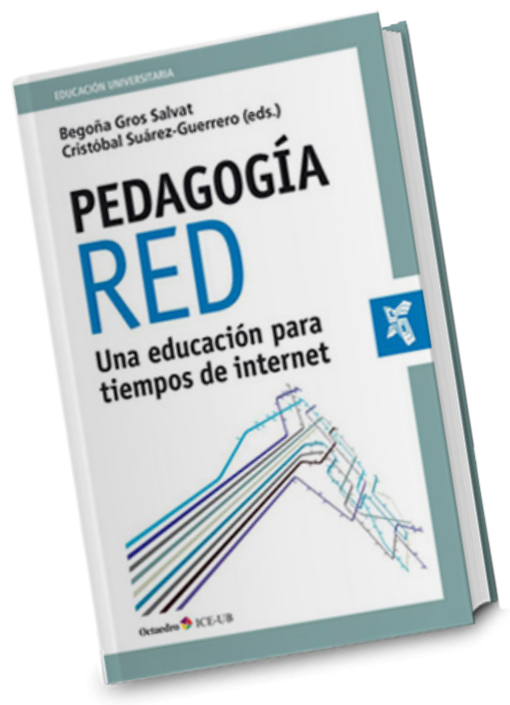

\author{
Por Julio César Mateus \\ (Universidad Pompeu Fabra, \\ Barcelona)
}

\footnotetext{
T 1 paso de la comunicación oral a la escrita significó la prime- ra ruptura del paradigma educativo por cuenta de una nueva tecnología. Como todo quiebre, no estuvo exento de críticos y obstáculos. El mismo Platón, por ejemplo, consideró la escritura perjudicial para la memoria, pues el proceso formativo se resiente al confiar una función orgánica a un dispositivo externo. Posteriormente, la imprenta y, siglos después, las tecnologías de comunicación de masas auspiciaron otras rupturas sustantivas con las formas de aprender. En ambos casos, cobró cada vez mayor relevancia el aprendizaje informal o invisible. La declaración firmada en la ciudad alemana de Grünwald, en 1982, por un grupo de investigadores convocados por la Unesco, daba cuenta de la cuestión aún en tiempos predigitales:
} 
En lugar de condenar o aprobar el indiscutible poder de los medios de comunicación, es forzoso aceptar como un hecho establecido su considerable impacto y su propagación a través del mundo y reconocer al mismo tiempo que constituyen un elemento importante de la cultura en el mundo contemporáneo.

El auge de la cultura audiovisual supuso la preocupación de muchos críticos - como los italianos Giovanni Sartori o Raffaele Simone- por la presunta degradación del conocimiento, pero también la aparición de otros intelectuales menos pesimistas, como Jesús Martín-Barbero, quien cree que el sistema de medios no es sino un "reto que pone al descubierto el carácter obsoleto de un modelo de comunicación escolar que, acosado por los cuatro costados, se coloca a la defensiva desfasándose aceleradamente de los procesos de producción y circulación del conocimiento que hoy dinamizan la sociedad".

El proceso de digitalización y, en particular, la aparición de internet - metamedio por excelencia - han provocado un cambio radical en las prácticas de producción y consumo informativo, cuyo impacto educativo, sin embargo, no acabamos de interpretar -o preferimos hacer limitándonos a la aplicación en sí-. Una vez más, críticos mordaces, como Nicholas Carr o Mario Vargas Llosa, señalan, con tintes distintos, que la desintermediación y profusión informativa desorganizan la cultura, mal acostumbrándonos a una interacción más superficial o degradando sus contenidos en favor del espectáculo. En la otra vereda, hallamos promotores más entusiastas del cambio y de las oportunidades que la instalación de la red de redes comporta. En ese contexto es donde leemos Pedagogía red. Una educación para tiempos de internet, libro multiautoral editado por los profesores Begoña Gros Salvat, de la Universitat Abierta de Cataluña, y Cristóbal Suárez-Guerrero, de la Universidad de Valencia, cuya finalidad es articular una reflexión que usa como eje la metáfora de la red y es aplicada especialmente al ámbito de la educación superior.

El libro está formado por ocho capítulos firmados por once investigadores que, desde diversas disciplinas, trascienden la tesis de internet como el dispositivo que facilita o soluciona problemas. Las propuestas del libro se instalan, más bien, en una línea vygotskiana que contextualiza los procesos de enseñanza-aprendizaje en los marcos del medio social y la cultura. Cada capítulo responde una pregunta, siguiendo el estilo mayéutico con el que Sócrates incentivaba la búsqueda de la verdad. Las preguntas que se abordan son estas: ¿cómo valorar lo que 
se aprende en red?, ¿cuándo aprenderlo?, ¿dónde?, ¿con quién?, ¿con qué?, ¿cómo?, ¿qué?, y ¿por qué hacerlo? Los propios editores advierten en la introducción que "la pedagogía también tiene esa vocación por buscar, gracias a las preguntas, la movilidad de las ideas y la crítica para ir más allá de la moda o el automatismo con que a veces se puede asumir internet en la educación".

En diversos apartados, los autores cuestionan los sentidos y valoraciones de los aprendizajes en la red en los terrenos formal e informal, haciendo hincapié en el desarrollo de capacidades. Precisamente qué capacidades son formadas y cómo son algunas de las cuestiones más interesantes. Del mismo modo, en varias páginas se discute el impacto de la disolución del espacio/tiempo y la aparición del aprendizaje ubicuo y asíncrono materializado en plataformas móviles, sistemas de gestión de aprendizaje virtual y fenómenos globales como el de los cursos en línea masivos y abiertos (mejor conocidos por sus siglas en inglés: MOOC).

Una de las ideas que atraviesa con fuerza los distintos capítulos es la del "aprendizaje en internet", que remite tanto al aprendizaje sobre la red como al aprendizaje en red. Del mismo modo, se insiste en la naturaleza social del aprendizaje, al tiempo que se presentan reflexiones en torno al sentido y las finalidades de la educación en la nueva ecología transmedial. Bien se señala en los párrafos introductorios:

Como aprender no es aséptico al entorno donde sucede, algo debemos exigir a la reflexión educativa para ir más allá de la sustitución de un recurso por otro. Lo radical del cambio es comprender que aprender puede estar enmarañado en una nueva capa de acción y representación en red.

Muchas publicaciones inundan las librerías con catálogos de herramientas tecnológicas vendidas como recursos didácticos, prescripciones sobre el uso idóneo de los medios y casos de éxito de innovaciones y emprendimientos difícilmente generalizables. Por si fuera poco, se reproducen mitos reduccionistas como el de los "nativos digitales", que han sido la coartada perfecta para persuadir a los educadores de aceptar con resignación una realidad donde siempre serán menos competentes tecnológicamente y menos necesarios pedagógicamente. Pocas publicaciones, sin embargo, reflexionan desde la propia teoría del aprendizaje sobre el impacto de los medios de comunicación, particularmente de internet. Quizá el mejor referente sea la propuesta del conectivismo desarrollada desde el mundo anglosajón por George Siemens y Stephen Downes, que plantea la importancia de 
las conexiones y los nodos en un mundo de conocimientos descentrados y caóticos. Concluyen estos autores que "nuestra habilidad para aprender lo que necesitamos mañana es más importante que lo que sabemos hoy".

Por lo anterior, el mayor aporte de investigadores como Julio Cabero, Diego Levis y Francesc Llorens, convocados por Begoña Gros Salvat y Cristóbal Suárez-Guerrero, es precisamente recordarnos la urgencia de comprender los medios, más que como artefactos materiales, como experiencias sociales, y cuestionar si nuestras prácticas docentes no siguen siendo más de lo mismo. La sentencia que suscribimos es clara: lo educativo debe preceder a lo tecnológico. 